\title{
Changes in Physical Activity and Eating Behavior after Coronavirus Pandemic 2019: An Online Survey of Elite Youth Korean Athletes
}

\author{
Jun-Young Sung', Sang-Sub Park' and Tae-Woong Oh ${ }^{2 *}$ \\ ${ }^{1}$ Republic of Korea Air Force Academy \\ ${ }^{2}$ Yongin University
}

\section{Article Info}

Received 2021.11.04.

Revised 2021.12.08.

Accepted 2021.12.23.

Correspondence*

Tae-Woong Oh

ohtw1972@gmail.com

\section{Key Words}

COVID-19,

Physical activity change,

Eating behavior change,

Elite athlete,

Questionnaire
PURPOSE This study aimed to investigate the effects of COVID-19 on elite youth athletes by investigating their activities and eating habits before and after the COVID-19 pandemic. METHODS This study included 917 elite adult athletes from 19 sports and were grouped into 6 . The questionnaire included items regarding demographics, physical activity, sleep, and eating habits before and after COVID-19. A total of 44 questions requiring subjective short answers were included. Statistical significance was set at $p<0.05$. RESULTS After COVID-19, vigorous and moderate activity decreased across all sports; however, light activity increased in almost sports. Time spent sitting increased across all sports. The difference in the number of meals consumed varied among sports, and the number of competitions decreased in all sports. CONCLUSIONS The COVID-19 pandemic appears to be finished but has not ended yet. Athletes must determine the best way to maintain their physical, physiological, and psychological states close to their original abilities. Determining this will provide the greatest impact on the return of athletes after COVID-19; this study will be helpful.

\section{서론}

2020년 3월 11일, 세계보건기구(WHO)는 우한에서 발생한 세계적인 전염병이 심각한 급성 호흡기 증후군 코로나바이러스(SARS-Covid2)를 유발한다고 선언했으며(WHO, 2020), 이는 국제적 차원의 공중 보건 비상상황을 요구하고 있다(Castañeda et al., 2020). 전 세계적 재난 상황에서 대한민국 역시 경제, 상업적 활동이 제한되었으며, 사회적 거리두기로 인해 일상생활 및 신체활동 역시 제약받는 실태이다.

COVID-19는 접촉 간에 발생하는 기침이나, 재채기 등의 분비물로 주로 전염되기에(Lu et al., 2020; World Health Organization, 2020), 신체적 거리가 가까운 신체활동, 스포츠 등의 활동은 제한적인 상황이다. 신체활동 및 스포츠 활동 제한은 신체적, 심리적 측면에서 부정적인 영향을 초래하며(Hallal et al., 2012; $\mathrm{Kim}, 2021$ ), 실재 COVID-19의 지속적 확산으로 사람들의 건강에 장기적인 위험성이 증가 되고 있다(Hoffmann et al., 2019). 또한,

(cc) This is an open-access article distributed under the terms of the Creative Commons Attribution Non-Commercial License (http://creativecommons.org/ licenses/by-nc/4.0/), which permits unrestricted non-commercial use, distribution, and reproduction in any medium, provided the original work is properly cited.
일상생활의 변화로 인한 활동량 감소 및 앉아있는 시간의 증가는 질병 발생 위험성을 가중시켜 새로운 위험요인으로 작용할 수 있다(Ammar et al., 2020; Frank et al., 2020, Ji et al., 2020).

일상생활을 영위하는 사람들뿐 아니라 COVID-19는 강도 높은 스포츠 활동을 하는 엘리트 스포츠 선수들에게도 부정적 영향으로 작용한다(Sarto et al., 2020). COVID-19 감염 시 스트레스 내성과 대처 전략에 밀접하게 관여하는 신경 내분비-면역 시스템이 심각하게 억제되는 것으로 밝혀졌으며(Cao, 2020), 이는 인체의 활동 및 기능에 매우 치명적이다. 또한, 스포츠 선수들의 특성상 반복적인 훈련이 필수적이지만, 사회적 거리두기로 인한 운동 시설이용 금지, 훈련 인원의 제약 등으로 선수들의 훈련 여건 자체가 마련되지 않고 있다. 그리고 COVID-19로 인해 모든 메가 이벤트(2020 도쿄 올림픽 등) 및 국내, 외 대회들의 개최 연기 및 취소 역시 엘리트 선수들에게 좋지 못한 소식으로, 경기를 준비한 선수들에게 신체적, 정서적, 정신적으로 부정적 영향을 미칠 수 있다(Engebretsen et al., 2014).

이와 같은 현상은 단순 훈련을 못 하고, 대회에 참가하지 못하는 것으로 그치는 것이 아니다. 불충분한 또는 부적절한 훈련 자극으로 인해 선수들의 운동기능 및 생리적 적응을 상실할 수 있고(Mujika \& Padilla, 2000), 선수들에게 정서적 고통과 심리적 장애 발생으로 인한(Reardon et al., 2019) 부상 위험성 증가 및 COVID-19 이후 
선수 복귀에 어려움을 겪을 수 있다(Sarto et al., 2020).

그렇기에 선수들의 컨디셔닝과 COVID-19 종결 후 선수들의 성공적 복귀를 위해 COVID-19 시대 선수들의 훈련량 및 식사, 컨디셔닝에 관한 연구가 필요하지만, 현재(Castañeda et al., 2020; Ammar et al., 2020; Sarto et al., 2020; Mehrsafar et al., 2020; Mann et al., 2020)와 같은 서구권 연구들이 주를 이루며, 한국을 포함한 아시아 지역 연구는 부족한 실정이다. 특히, 성장기에 있는 엘리트 청소년선수들의 실질적 정보를 자료화한 연구는 전무한 실정이다.

따라서 이 연구의 목적은 COVID-19 이전과 COVID-19 이후 엘 리트 청소년선수들의 활동량 및 식습관을 조사하여 선수들의 변화를 확인하고, 시합참가 여부 등을 파악하여 국내 엘리트 청소년선수들의 COVID-19 이후 데이터베이스를 구축하는 것을 목표로 한다. 그리고 이를 바탕으로 해외 사례들과 비교를 통해, 선수들의 경기력 유지 및 COVID-19 종료 후 선수들의 성공적인 복귀방안을 제시하는 데 목적 이 있다.

\section{연구 방법}

\section{연구대상}

이 연구는 대한체육회에 3 년 이상 선수등록이 되어있는 14 세 이상 20세 미만 엘리트 청소년선수를 대상으로 진행하였다. 설문지는 단순 무작위 추출법(simple random sampling)을 활용하여 각 종목 단체 사무국 및 선수단 지도자를 통해 온라인으로 배포되었으며, 응답된 설문지 중 불성실 응답으로 판단되는 78부를 제외하고 총 917부가 자료 분석에 이용되었다. 참여 종목은 총 19종목이었으며 종목특성에 따라 개인종목(individual sports), 기록종목(record sports), 라켓 종목(racket sports), 구기종목(ball sports), 투기 종목(combat sports), 동계종목(winter sports)으로 구분하였다. 연구대상자의 인구통계학적 특성은 〈Table 1〉과 같다.

\section{참여자 개인정보 보호 및 참여 동의}

이 연구의 모든 설문은 COVID-19발생 이후 진행되었다. 설문지 시작 전 연구 참여자들은 모든 데이터는 연구 목적으로만 사용될 것이라는 설명을 듣고, 시작 전 자발적으로 이 연구에 참여한다는 항목에 동의하였다. 또한, 설문 시작 전 연구의 취지와 목적을 설명하고, 참가자들에게 솔직하게 답변해 줄것을 요청하였다. 참여자의 답변은 Google의 개인정보보호정책(https://policies.google.com/privacy ?hl=en)에 따라 익명으로 처리되어 진행되었다. 설문지는 참여자가 자신의 성명과 주소, 연락처를 제공하지 않도록 설정되었다. 설문지 작성 절차 어느 단계에서든 연구 참여를 중단할 수 있었으며, 이런 경우 응답 내용이 제출되지 않도록 설정되었다. 모든 문항을 완료하면 참여자는 “제출” 버튼을 클릭하여 응답을 제출하였다.

\section{측정도구}

이 연구에서 사용된 설문지는 연구에 이용된 변수들과 관련되어 기존 연구에서 쓰인 문항들을 수정, 보완하여 작성되었다. 설문지는
Table 1. The demographic characteristics of the participants

\begin{tabular}{|c|c|c|c|}
\hline Variables & & $\mathrm{n}$ & $\%$ \\
\hline \multirow{2}{*}{ Gender } & Male & 723 & 78.8 \\
\hline & Female & 194 & 21.2 \\
\hline \multirow{2}{*}{$\begin{array}{c}\text { Age } \\
\text { (years) }\end{array}$} & $14-16$ & 160 & 17.6 \\
\hline & $17-19$ & 757 & 82.4 \\
\hline \multirow{2}{*}{ Institution } & Middle school & 162 & 17.7 \\
\hline & High school & 755 & 82.3 \\
\hline \multirow{4}{*}{$\begin{array}{l}\text { Hight } \\
(\mathrm{cm})\end{array}$} & $<160$ & 60 & 6.5 \\
\hline & $161-170$ & 275 & 30.0 \\
\hline & $171-180$ & 461 & 50.3 \\
\hline & $>181$ & 121 & 13.2 \\
\hline \multirow{5}{*}{$\begin{array}{l}\text { Weight } \\
\text { (kg) }\end{array}$} & $<50$ & 53 & 5.8 \\
\hline & $51-60$ & 181 & 19.7 \\
\hline & $61-70$ & 227 & 24.8 \\
\hline & $71-80$ & 302 & 32.9 \\
\hline & $>81$ & 154 & 16.8 \\
\hline \multirow{6}{*}{ Sports } & Individual sports & 56 & 6.1 \\
\hline & Record sports & 134 & 14.6 \\
\hline & Racket sports & 53 & 5.8 \\
\hline & Ball sports & 270 & 29.4 \\
\hline & Combat sports & 349 & 38.1 \\
\hline & Winter sports & 55 & 6.0 \\
\hline \multirow{3}{*}{$\begin{array}{l}\text { Career } \\
\text { (years) }\end{array}$} & 3 & 283 & 30.9 \\
\hline & $4-7$ & 376 & 41.0 \\
\hline & $>8$ & 258 & 29.1 \\
\hline \multirow{3}{*}{$\begin{array}{l}\text { Winning } \\
\text { career }\end{array}$} & International & 13 & 1.4 \\
\hline & National & 586 & 63.9 \\
\hline & None & 318 & 34.7 \\
\hline \multirow{2}{*}{ Date status } & Single & 488 & 53.2 \\
\hline & Couple & 429 & 46.8 \\
\hline \multirow{2}{*}{$\begin{array}{c}\text { Smoking } \\
\text { status }\end{array}$} & Smoking & 68 & 7.4 \\
\hline & None & 849 & 92.6 \\
\hline \multirow{2}{*}{ Drink status } & Drink & 110 & 11.9 \\
\hline & None & 807 & 88.1 \\
\hline \multirow{4}{*}{ Health state } & Healthy & 634 & 69.1 \\
\hline & Injuries & 268 & 29.2 \\
\hline & With risk factors for disease & 15 & 1.7 \\
\hline & Total & 917 & 100.0 \\
\hline
\end{tabular}


인구통계학적 요인과 COVID-19 이전-이후 각 신체활동과 수면, 식습관에 관한 문항들로 구성되었으며, 인구통계학적 요인(12문항), 신체활동 및 수면(16문항), 식습관(8문항), 체중변화(8문항) 총 44 문항을 주관식 단답형을 활용하여 측정하였다.

인구통계학적 요인 12문항은 Ammar등(2020)의 연구에서 이용되었던 문항을 본 연구의 대상과 상황에 맞게 수정, 보완하여 사용하였다.

신체활동과 수면에 대한 16문항은 국제형 신체활동에 대한 짧은 설문지(IPAQ-SF)와 수면 품질(pittsburgh, 수면 품질 지수)에 대한 설문지(Craig et al., 2003; Fat et al., 2017; Ammar et al., 2020; Ammar et al., 2021)의 문항을 본 연구의 대상과 상황에 맞게 수정, 보완하여 사용하였다.

식습관에 관한 8문항은 Thabrew등(2018)과 Ammar등(2021)의 연구에서 이용되었던 문항을 본 연구의 대상과 상황에 맞게 수정, 보완하여 사용하였다.

마지막으로 시합참여 8문항은 선행연구의 문항 활용이 어렵다고 판단되어 전문가 집단의 타당성 검증을 통해 새로 생성하였다.

\section{측정도구의 타당성 및 신뢰성 검증}

연구에 이용된 측정 도구의 타당성 검증은 선행 연구를 통해 이미 증명된 바 있다(Castañeda et al., 2020; Ammar et al., 2020). 따라서 이 연구에서는 번역 오류에 대한 내용타당성검증 만을 실시하였다. 운동생리학, 스포츠 영양학, 운동 처방, 트레이닝방법론 관련 교수 및 연구자, 그리고 선수 지도자 및 현역 선수들로 구성된 전문가 집단을 대상으로 설문 문항들이 측정개념을 적합하게 측정하는지 내용상으로 검토하는 검증 절차를 거쳤다.

또한, 설문지의 신뢰성 평가는 연구 시작 전 연구진을 통해 사전 실험으로 진행했다(Ammar et al., 2021). 사전 실험 결과 시험 신뢰도 계수에 적합한 것을 확인할 수 있었다( $\mathrm{r}=0.84-0.96)$.

\section{통계처리}

연구의 자료 분석을 위해 SPSS WIN 23.0 프로그램을 사용하였다. 기술통계를 사용하여 각 질문과 질문에 대한 반응의 비율을 정의하였으며, 각 설문지의 총 점수에 대한 모든 평균과 표준편차를 산출하었다. COVID-19 이전-이후 각 신체활동과 수면, 식습관변화를 확인하기 위해 paired $t$-test를 실시하였다. 모든 자료의 통계적 유의수준 $p<0.05$ 로 설정하였다.

\section{연구결과}

\section{COVID-19 이후 고강도 신체활동량의 변화}

COVID-19 이후 고강도 신체활동 횟수는 개인종목을 제외한 모든 종목에서 감소하였다. 그중 종목종합( $p<.001)$, 기록종목 $(p=.041)$, 구기종목 $(p=.022)$, 투기종목 $(p=.007)$ 에서 통계적으로 유의한 차이를 보였다.

고강도 신체활동 시간은 종목종합을 포함한 7개 종목에서 모두 COVID-19 이후 감소한 것을 확인할 수 있었으며 종목종합(p<.001),
개인종목( $p=.009)$, 구기종목( $p<.001)$, 라켓 종목 $(p=.021)$, 투기 종목(p<.001)에서 통계적으로 유의한 차이를 나타냈다〈Table 2〉.

\section{COVID-19 이후 중강도 신체활동량의 변화}

COVID-19 이후 중강도 신체활동 횟수 역시 개인종목을 제외한 모든 종목에서 감소하였으며, 종목종합이( $p=.008)$ 기록 종목( $p=.042)$ 으로 통계적으로 유의한 차이를 나타냈다.

중강도 신체활동 시간의 경우 개인종목이 ( $p=.006)$ 으로 통계적으로 유의한 차이를 나타냈다〈Table 2〉.

\section{COVID-19 이후 저강도 신체활동량의 변화}

저강도 신체활동 횟수의 경우 개인종목은 $(p=.740)$, 기록종목은( $p<.021)$, 라켓 종목은 $(p<.001)$ 로 감소하였으나, 종목종합 $(p<.001)$ 구기종목은( $p<.001)$, 투기 종목은( $p<.001)$, 동계종목은 $(p=.007)$ 로 증가한 것을 확인할 수 있었다.

저강도 신체활동 시간은 라켓 종목을 제외한 모든 종목에서 증가하였으며, 종목종합( $p<.001)$, 구기종목 $(p=.019)$ 과 투기 종목(p〈.001)에서 통계적으로 유의한 차이를 나타냈다〈Table 2〉.

\section{COVID-19 이후 앉아 보낸 시간의 변화}

COVID-19 이후 앉아 보낸 시간은 종목종합을 포함한 모든 종목에서 증가하였다. 또한, 종목종합( $p<.001)$ 개인종목(p<.001), 기록종목( $p<.001)$, 구기종목( $p<.001)$, 라켓 종목 $(p<.007)$, 투기 종목(p<.001), 동계종목 $p<.001)$ 으로 통계적으로 유의한 차이를 나타냈다〈Table 3$\rangle$.

\section{COVID-19 이후 누워 보낸 시간의 변화}

누워서 보낸 시간의 경우 동계종목을 제외한 모든 종목에서 증가한 것을 확인할 수 있었다. 그러나 투기종목 $(p=.048)$ 과 동계종목 $(p=.018)$ 을 제외한 나머지 종목들에서는 통계적으로 유의한 차이는 나타나지 않았다〈Table 3〉.

\section{COVID-19 이후 식습관의 변화}

선수들의 식습관 변화의 경우 〈Table 3〉에서 확인할 수 있다. 먼저 아침 식사 횟수는 종목종합 개인종목, 기록종목, 라켓 종목, 투기 종목이 증가했으며, 구기 종목과 동계종목은 감소한 것을 확인할 수 있었다. 그중 기록종목 $(p=.018)$ 과 구기종목 $(p=.049)$, 라켓 종목( $p=.034)$ 에서 통계적으로 유의한 차이를 보였다.

점심 식사횟수의 경우 COVID-19 이후 식사량의 큰 변화를 보이지 않았으며, 모든 종목에서 통계적으로 유의한 차이를 나타내지 않았다.

저녁 식사 역시 점심 식사와 마찬가지로 COVID-19 이후 식사량의 큰 변화를 보이지 않았다. 오직 개인종목만이 6.22 1.58 에서 $6.33 \pm 1.37$ 로 증가하였으며, 통계적으로 유의한 차이를 나타냈다 $(p=.013)$. 
Table 2. Changes in daily activity after COVID-19

(Mean \pm SD)

\begin{tabular}{|c|c|c|c|c|c|}
\hline Variables & Sports & Pre COVID-19 & Post COVID-19 & $t$ & $p$ \\
\hline \multirow{7}{*}{$\begin{array}{l}\text { Vigorous activity } \\
\text { raps/week }\end{array}$} & Sports total & $5.78 \pm 2.77$ & $5.48 \pm 2.71$ & -3.353 & .001 \\
\hline & Individual sports & $4.09 \pm 1.95$ & $4.18 \pm 2.06$ & -.396 & .694 \\
\hline & Record sports & $5.45 \pm 1.99$ & $5.07 \pm 1.68$ & -2.077 & .041 \\
\hline & Ball sports & $6.22 \pm 3.54$ & $5.74 \pm 3.27$ & -2.310 & .022 \\
\hline & Racket sports & $6.78 \pm 3.71$ & $6.63 \pm 4.06$ & -.232 & .818 \\
\hline & Combat sports & $5.73 \pm 1.85$ & $5.44 \pm 2.07$ & -2.699 & .007 \\
\hline & Winter sports & $5.79 \pm 3.52$ & $5.72 \pm 4.19$ & .505 & .617 \\
\hline \multirow{7}{*}{$\begin{array}{l}\text { Vigorous activity } \\
\text { mins/day }\end{array}$} & Sports total & $198.05 \pm 104.28$ & $180.58 \pm 103.83$ & -6.182 & $<.001$ \\
\hline & Individual sports & $175.00 \pm 143.21$ & $143.00 \pm 142.85$ & -2.713 & .009 \\
\hline & Record sports & $214.41 \pm 88.91$ & $210.54 \pm 92.61$ & -.576 & .566 \\
\hline & Ball sports & $204.97 \pm 113.69$ & $183.49 \pm 113.11$ & -3.767 & $<.001$ \\
\hline & Racket sports & $250.16 \pm 110.32$ & $222.88 \pm 123.66$ & -2.389 & .021 \\
\hline & Combat sports & $182.66 \pm 86.28$ & $166.84 \pm 85.39$ & -3.896 & $<.001$ \\
\hline & Winter sports & $195.90 \pm 119.81$ & $180.77 \pm 93.46$ & -1.012 & .317 \\
\hline \multirow{7}{*}{$\begin{array}{l}\text { Moderate activity } \\
\text { raps/week }\end{array}$} & Sports total & $4.91 \pm 2.87$ & $4.63 \pm 1.91$ & 2.677 & .008 \\
\hline & Individual sports & $4.76 \pm 1.97$ & $4.79 \pm 1.79$ & .000 & 1.000 \\
\hline & Record sports & $4.39 \pm 3.09$ & $3.80 \pm 1.97$ & 2.059 & .042 \\
\hline & Ball sports & $5.11 \pm 3.29$ & $4.86 \pm 2.05$ & 1.194 & .234 \\
\hline & Racket sports & $5.31 \pm 1.74$ & $5.02 \pm 1.63$ & .944 & .351 \\
\hline & Combat sports & $5.04 \pm 2.82$ & $4.79 \pm 1.77$ & 1.453 & .148 \\
\hline & Winter sports & $4.18 \pm 1.79$ & $4.16 \pm 1.81$ & .124 & .902 \\
\hline \multirow{7}{*}{$\begin{array}{l}\text { Moderate activity } \\
\text { mins/day }\end{array}$} & Sports total & $150.74 \pm 102.28$ & $151.27 \pm 99.21$ & -.152 & .879 \\
\hline & Individual sports & $191.42 \pm 131.01$ & $125.24 \pm 107.76$ & 2.886 & .006 \\
\hline & Record sports & $148.46 \pm 75.74$ & $146.31 \pm 73.72$ & .353 & .725 \\
\hline & Ball sports & $155.20 \pm 102.85$ & $144.17 \pm 103.67$ & -1.624 & .106 \\
\hline & Racket sports & $211.08 \pm 131.82$ & $201.8 \pm 133.91$ & -1.253 & .218 \\
\hline & Combat sports & $148.82 \pm 96.62$ & $143.54 \pm 96.26$ & -.970 & .333 \\
\hline & Winter sports & $145.26 \pm 109.73$ & $129.63 \pm 93.38$ & 1.570 & .125 \\
\hline \multirow{7}{*}{$\begin{array}{l}\text { Light activity } \\
\text { raps/week }\end{array}$} & Sports total & $4.49 \pm 2.89$ & $6.55 \pm 6.36$ & 8.366 & $<.001$ \\
\hline & Individual sports & $4.77 \pm 3.08$ & $4.68 \pm 2.85$ & .335 & .740 \\
\hline & Record sports & $5.32 \pm 6.16$ & $3.41 \pm 2.41$ & 2.363 & .021 \\
\hline & Ball sports & $4.64 \pm 2.73$ & $7.07 \pm 6.86$ & 5.114 & $<.001$ \\
\hline & Racket sports & $10.15 \pm 7.88$ & $4.73 \pm 2.26$ & 4.549 & $<.001$ \\
\hline & Combat sports & $4.77 \pm 3.20$ & $6.13 \pm 5.68$ & 4.019 & $<.001$ \\
\hline & Winter sports & $3.16 \pm 2.39$ & $7.27 \pm 8.00$ & 2.922 & .007 \\
\hline \multirow{7}{*}{$\begin{array}{l}\text { Light activity } \\
\text { mins/day }\end{array}$} & Sports total & $133.16 \pm 115.28$ & $156.16 \pm 138.17$ & -5.149 & $<.001$ \\
\hline & Individual sports & $208.68 \pm 137.15$ & $240.11 \pm 156.35$ & -1.473 & .149 \\
\hline & Record sports & $122.08 \pm 104.31$ & $128.82 \pm 97.39$ & -.707 & .482 \\
\hline & Ball sports & $132.66 \pm 123.08$ & $147.92 \pm 111.04$ & -2.371 & .019 \\
\hline & Racket sports & $225.01 \pm 137.37$ & $187.81 \pm 124.27$ & -1.892 & .068 \\
\hline & Combat sports & $121.08 \pm 102.56$ & $154.10 \pm 161.80$ & -3.869 & $<.001$ \\
\hline & Winter sports & $111.29 \pm 29$ & $104.83 \pm 96.97$ & -.771 & .447 \\
\hline
\end{tabular}




\section{COVID-19 이후 시합참가 횟수의 변화}

COVID-19 이후 시합참가횟수는 모든 종목에서 감소하였음을 확인할 수 있었다. 구기종목을 제외한 종목종합(p〈.001), 개인종목(p<.001), 기록종목( $p<.001)$, 라켓 종목( $p=.026)$, 투기종목 $(p<.001)$, 동계종목( $p=022)$ 에서는 통계적으로 유의한 차이를 보였다〈Table 3〉.

\section{논의}

이 연구는 COVID-19 이전과 COVID-19 이후 엘리트 청소년선수들의 활동량 및 식습관, 시합참가 여부 등을 파악하여 국내 엘리트 청소년선수들의 현재 데이터베이스를 구축하여, COVID-19 종료 뒤 선수들의 성공적인 복귀방안을 제시하는 데 목적이 있다.

\section{COVID-19 이후 신체 활동량의 변화}

현재 COVID-19의 영향을 받는 신체활동 참여 제한은 각국 정부 정책과 관련이 있다. Hossain등(2020)에 따르면 다른 지역 정책과 사회-경제적 요인이 신체 활동량 차이와 관련이 있다는 것이 입증되었다. 이러한 영향은 일반 시민뿐만 아닌 엘리트 선수들에게도 적용된다. 운동선수들은 일반인보다 질병 혹은 사망 위험이 낮지만(Wu \& McGoogan, 2020), 사망 위험도가 높은 사람들의 보호를 위해 엘리트 선수들의 활동 제한 역시 필수적으로 적용된다(Brett \& Irfan, 2020).

이 연구의 COVID-19 이후 고강도 신체활동의 경우 개인종목을 제외한 모든 종목에서 감소하였다. 현재 COVID-19로 인해 스포츠를 포함한 신체활동 참여에 큰 제한이 있으며, 선행연구에서도 고강도 신체활동이 감소하였음을 확인할 수 있었다(Castañeda et al., 2020; Ammar et al., 2020; Sarto et al., 2020).

이러한 결과는 한국을 포함한 전 세계적으로 감염방지를 위한 사회적 거리 두기를 실시하고 있고, 훈련시설 이용금지 및 다인 집합금지 등으로 인한 활동량 감소로 판단된다. 또한, 고강도 신체활동 시간이 많은 '엘리트 선수’라는 특성상 고강도 신체활동 시간이 일상생활을 하는 일반인에 비해 두드러지게 감소한 것으로 판단된다.

반면에 중강도 신체활동에는 큰 변화를 보이지 않았으며, 저강도 신체활동의 경우 오히려 COVID-19 이전보다 증가한 것을 확인할 수 있었다. 현재 엘리트 청소년 선수들은 신체활동이 제한적인 상황이고, 단체로 모여서 하는 훈련보다 개개인이 별개로 실시하는 훈련이 주를 이루고 있다.

이처럼 엘리트 선수들이 모든 경기를 중단하도록 강요받는 것은 제2차 세계대전 이후 처음이다. COVID-19라는 특수한 상황 속에서 대부분의 엘리트 선수들은 집에서 혼자, 특히 지도자 없이 훈련을 해야 한다(Sarto et al., 2020). 해외 일부 엘리트 스포츠 팀들은 선수들에게 홈 기반 훈련 프로그램 및 트레이너가 주도하는 온라인 훈련 프로그램을 제공하고 있지만(Toresdahl \& Asif 2020; Jukic et al., 2020; Yousfi et al., 2020), 전문 스포츠 시설이 없을 경우 특정 스포츠만의 훈련 및 전략을 실시하기 어렵기에 정상적인 상황과 동등한 훈련을 제공하기가 어려운 것이 현실이다(Ammar et al., 2021).
국내의 상황은 더욱 열악하다. 국내 엘리트 선수들은 대부분 혼자 운동을 수행하고 있으며, 이는 부절절한 운동 수행으로 연결 될 수 있다. Mujika와 Padilla(2020)은 COVID-19로 인해 자택에서 운동을 실시하는 운동선수는 불충분하거나 부적절한 훈련 자극의 결과로 일정 수준의 훈련 중단(즉, 훈련 유도 형태학적 및 생리학적 적응의 부분 또는 전체 손실)에 노출될 가능성이 있다고 보고하였다. 즉 정확한 훈련정보의 부족이 저강도 신체활동의 증가로 나타난 것이라 판단되며, 엘리트 청소년 선수들의 훈련유지 및 컨디션 조절을 위해 보다 안전한 대면 훈련 방안 마련 및 온라인 훈련 프로그램이 제공되어야 하고, 관련연구가 필요할 것으로 판단된다.

\section{COVID-19 이후 일상생활의 변화}

청소년선수들의 앉아있는 시간은 평균 약 120 분 증가하였으며, COVID-19로 인해 집에 머무르는 시간의 증가로 앉아있는 시간이 증가했음을 확인할 수 있다(Castañeda et al., 2020). 지속적으로 비대면 환경에서 진행되는 온라인 학습 역시 앉아있는 시간을 증가시킨 원인으로 볼 수 있다(Chen et al., 2020).

또한 Bauman et al.(2012)의 '사회생태학적 모델'에 따르면 사회적 또는 환경적 장벽이 비활성 라이프 스타일(사회적 고립, 외로움)을 촉진하는 비교 가능한 변인에서 보다 많은 좌식활동 시 더 적은 신체활동 시간이 지속된다고 보고하였다(Schrempft et al., 2019; Kobayashi et al., 2018). 따라서 COVID-19 의한 비자발적인 장기 체류는 앉아서 지내는 행동을 부추길 수 있으며, 이 연구의 결과와 일치하는 것을 확인할 수 있다.

누워있는 시간의 경우 COVID-19 이전과 이후에서 두 종목(투기 종목, 동계종목)을 제외하면 통계적인 차이를 보이지 않았다. 이는 엘리트 선수들의 규칙적인 생활패턴이 유지되어 훈련이 없어도 선수들이 기본 수면시간은 준수하며 생활한 결과라 판단된다.

COVID-19 이후 식습관의 변화는 개인종목이 아침, 점심, 저녁 모두 식사횟수가 증가한 것으로 나타났다. 이외에도 기록종목과 라켓 종목에서 아침식사횟수가 증가된 것을 확인할 수 있었다. 선행연구에 따르면 COVID-19로 인해 자택대기 시간이 길어질수록 식사량과 횟수가 중가 한다는 결과를 확인할 수 있다(Antunes et al., 2020; Gallo et al., 2020; Di Renzo et al., 2020). 이는 감정상태와 연관 지어 설명 할 수 있으며, 활동량 감소 및 사회적 유대감 감소 역시 식사량 증가로 이어졌다 판단된다.

또한 이 연구를 통해 선수들의 일상생활 변화를 확인하였고, 연구 결과 COVID-19가 전 세계 라이프스타일에 큰 영향을 미칠 수 있다는(Oliveira et al., 2020; Ammar et al., 2020) 최근 연구와 일치하는 것을 확인할 수 있었다.

\section{COVID-19 이후 시합참가 횟수의 변화}

COVID-19로 인해 많은 경기들이 취소 혹은 연기되었다. 해외의 경우 2020 도쿄 올림픽은 1년 연기되어 2021년에 개최되었으며, 실행되는 경기도 무관중경기로 진행되고 있다. 한국은 해외에 비해 사정이 나은 실정이다. 세계적인 대유행 상황에서 한국은 효율적인 방역 통제에 성공하였고, 2020년부터 프로리그를 개막하여 운영 중에 있다. 프로스포츠뿐만 아닌 다른 엘리트 스포츠들도 방역수칙 준수 하에 경기를 진행하고 있지만, COVID-19에 비해 경기횟수가 
Table 3. Changes in life style after COVID-19

(Mean \pm SD)

\begin{tabular}{|c|c|c|c|c|c|}
\hline Variables & Sports & Pre COVID-19 & Post COVID-19 & $t$ & $p$ \\
\hline \multirow{7}{*}{$\begin{array}{l}\text { Sitting } \\
\text { mins/day }\end{array}$} & Sports total & $232.77 \pm 168.02$ & $318.36 \pm 126.72$ & -13.666 & $<.001$ \\
\hline & Individual sports & $150.00 \pm 155.15$ & $297.69 \pm 110.81$ & -5.829 & $<.001$ \\
\hline & Record sports & $214.28 \pm 146.57$ & $282.67 \pm 93.58$ & -5.492 & $<.001$ \\
\hline & Ball sports & $223.62 \pm 166.18$ & $295.92 \pm 135.32$ & -6.166 & $<.001$ \\
\hline & Racket sports & $250.76 \pm 171.85$ & $318.46 \pm 141.82$ & -2.874 & .007 \\
\hline & Combat sports & $262.12 \pm 168.93$ & $346.52 \pm 122.22$ & -8.103 & $<.001$ \\
\hline & Winter sports & $213.48 \pm 194.77$ & $362.79 \pm 140.37$ & -4.813 & $<.001$ \\
\hline \multirow{7}{*}{$\begin{array}{l}\text { Lying } \\
\text { mins/day }\end{array}$} & Sports total & $440.49 \pm 152.06$ & $444.52 \pm 148.69$ & -1.191 & .234 \\
\hline & Individual sports & $440.81 \pm 124.47$ & $451.60 \pm 143.30$ & -1.575 & .122 \\
\hline & Record sports & $405.40 \pm 179.25$ & $412.11 \pm 164.22$ & -.735 & .464 \\
\hline & Ball sports & $455.23 \pm 154.01$ & $459.01 \pm 152.56$ & .595 & .553 \\
\hline & Racket sports & $383.07 \pm 156.71$ & $395.38 \pm 156.71$ & -1.016 & .316 \\
\hline & Combat sports & $451.73 \pm 142.71$ & $463.13 \pm 130.69$ & -2.964 & .048 \\
\hline & Winter sports & $412.50 \pm 130.45$ & $382.50 \pm 141.65$ & 2.469 & .018 \\
\hline
\end{tabular}

Table 4. Changes in eating behaviors and the number of competitions after COVID-19

(Mean \pm SD)

\begin{tabular}{|c|c|c|c|c|c|}
\hline Variables & Sports & Pre COVID-19 & Post COVID-19 & $t$ & $p$ \\
\hline \multirow{7}{*}{$\begin{array}{c}\text { Breakfast } \\
\text { days/week }\end{array}$} & Sports total & $4.97 \pm 2.32$ & $4.98 \pm 2.37$ & -.385 & .701 \\
\hline & Individual sports & $5.33 \pm 1.81$ & $5.55 \pm 2.19$ & -1.693 & .096 \\
\hline & Record sports & $5.86 \pm 1.60$ & $6.04 \pm 1.38$ & -2.406 & .018 \\
\hline & Ball sports & $4.86 \pm 2.39$ & $4.69 \pm 2.57$ & 1.974 & .049 \\
\hline & Racket sports & $4.62 \pm 2.14$ & $4.95 \pm 2.01$ & -2.187 & .034 \\
\hline & Combat sports & $4.67 \pm 2.51$ & $4.69 \pm 2.57$ & -.469 & .639 \\
\hline & Winter sports & $5.23 \pm 1.89$ & $5.21 \pm 2.06$ & .141 & .888 \\
\hline \multirow{7}{*}{$\begin{array}{c}\text { Lunch } \\
\text { days/week }\end{array}$} & Sports total & $6.65 \pm 0.98$ & $6.66 \pm 0.94$ & -.533 & .594 \\
\hline & Individual sports & $6.33 \pm 1.45$ & $6.44 \pm 1.38$ & -1.946 & .057 \\
\hline & Record sports & $6.83 \pm 0.46$ & $6.81 \pm 0.60$ & .425 & .672 \\
\hline & Ball sports & $6.77 \pm 0.79$ & $6.79 \pm 0.79$ & -.577 & .565 \\
\hline & Racket sports & $5.76 \pm 1.80$ & $6.00 \pm 1.65$ & -1.911 & .062 \\
\hline & Combat sports & $6.71 \pm 0.89$ & $6.70 \pm 0.82$ & .091 & .928 \\
\hline & Winter sports & $6.44 \pm 1.14$ & $6.28 \pm 1.19$ & .739 & .463 \\
\hline \multirow{7}{*}{$\begin{array}{c}\text { Dinner } \\
\text { days/week }\end{array}$} & Sports total & $6.66 \pm 1.01$ & $6.66 \pm 1.01$ & .000 & 1.000 \\
\hline & Individual sports & $6.22 \pm 1.58$ & $6.33 \pm 1.37$ & -2.574 & .013 \\
\hline & Record sports & $6.85 \pm 0.57$ & $6.83 \pm 0.56$ & .815 & .417 \\
\hline & Ball sports & $6.82 \pm 0.66$ & $6.88 \pm 0.56$ & -2.078 & .039 \\
\hline & Racket sports & $6.11 \pm 1.35$ & $6.19 \pm 1.31$ & -2.069 & .044 \\
\hline & Combat sports & $6.67 \pm 0.77$ & $6.64 \pm 1.04$ & .527 & .599 \\
\hline & Winter sports & $6.30 \pm 1.60$ & $6.02 \pm 1.89$ & 1.815 & .070 \\
\hline \multirow{7}{*}{$\begin{array}{c}\text { Competition } \\
\text { a year }\end{array}$} & Sports total & $5.37 \pm 3.25$ & $4.76 \pm 3.49$ & 6.063 & $<.001$ \\
\hline & Individual sports & $6.44 \pm 2.92$ & $4.16 \pm 2.21$ & 5.931 & $<.001$ \\
\hline & Record sports & $4.59 \pm 1.92$ & $3.55 \pm 1.93$ & 5.775 & $<.001$ \\
\hline & Ball sports & $5.83 \pm 4.07$ & $5.76 \pm 4.96$ & .280 & .780 \\
\hline & Racket sports & $5.51 \pm 3.32$ & $5.06 \pm 3.12$ & 1.142 & 0.26 \\
\hline & Combat sports & $5.05 \pm 2.82$ & $4.61 \pm 2.74$ & 3.871 & $<.001$ \\
\hline & Winter sports & $5.88 \pm 3.91$ & $4.60 \pm 2.52$ & 2.382 & .022 \\
\hline
\end{tabular}


적어진 것은 사실이다. 이는 COVID-19라는 전 세계적 대유행 상황에서 어쩔 수 없는 부분이기에 선수들의 훈련량 유지 및 건강관리를 최우선으로 관리해야 된다 판단된다.

COVID-19가 종식되면, 선수들은 오히려 강해진 훈련량과 경기 일정에 대한 준비가 되어 있지 않을 수 있다. 그렇기에 시즌 내 신경근육과 심폐 기능 회복 및 종목별 특성에 적합한 컨디셔닝 기간이 필요할 것으로 판단된다. 이를 통해 일반적으로 발생하는 부상 위험을 잠재적으로 줄일 수 있으며(Silva et al., 2016; Sarto et al., 2020), 선수들의 경기력 회복에도 긍정적인 영향을 미치리라 판단된다.

\section{결론 및 제언}

COVID-19의 대유행은 끝난 듯 보이지만 아직 종결되지 않았다. COVID-19 기간 동안 선수들의 삶은 여러 영향을 받으며, 여태껏 경험한 적 없는 새로운 생활방식으로 인해 선수들은 큰 생리적, 심리적 영향을 받는다. 특히 성장기에 있는 청소년 선수들은 성인선수들에 비해 그 영향이 더욱 크게 다가올 것이다. 운동선수들은 본인의 기량을 유지하기 위해 훈련, 영양, 일상의 리듬과 충분한 수면을 취해야 한다는 것은 명백한 사실이다. 그러나 지속적인 COVID-19 상황에서 일상적인 훈련을 수행하는 것은 불가능하다. 따라서, 운동선수들은 자신의 신체적, 생리적, 심리적 수준을 본래 기량에 가깝게 유지하기 위한 최적의 방법을 찾는 것이 중요하다. 또한 이는 COVID-19종결 이후 선수들의 복귀에 가장 큰 영향을 미칠 것이다.

그렇기에 선수 자신이 본인의 신체 상태를 정확히 이해하고, 훈련과 생활을 하는 것이 중요하며, 지도자와 부모들은 청소년기에 있는 엘리트 선수들에의 일상과 식습관에 변화가 생기지 않도록 예의주시해야 할 것이다. 또한, 비대면 환경에서 선수들에게 정확한 훈련정보가 전달될 수 있도록 비대면 교육방식의 개발 및 적극적인 활용이 필요하다 판단된다. 


\section{참고문헌}

Ammar, A., Chtourou, H., Boukhris, O., Trabelsi, K., Masmoudi, L., Brach, M., ... \& ECLB-COVID19 Consortium. (2020). COVID-19 home confinement negatively impacts social participation and life satisfaction: a worldwide multicenter study. International Journal of Environmental Research and Public Health, 17(17), 6237.

Ammar, A., Mueller, P., Trabelsi, K., Chtourou, H., Boukhris, O., Masmoudi, L., ... \& ECLB-COVID19 Consortium. (2020). Psychological consequences of COVID-19 home confinement: The ECLB-COVID19 multicenter study. PloS One, 15(11), e0240204.

Ammar, A., Trabelsi, K., Brach, M., Chtourou, H., Boukhris, O., Masmoudi, L., ... \& Batatia, H. (2021). Effects of home confinement on mental health and lifestyle behaviours during the COVID-19 outbreak: insights from the ECLB-COVID19 multicentre study. Biology of Sport, 38(1), 9.

Antunes, R., Frontini, R., Amaro, N., Salvador, R., Matos, R., Morouço, P., \& Rebelo-Gonçalves, R. (2020). Exploring lifestyle habits, physical activity, anxiety and basic psychological needs in a sample of Portuguese adults during COVID-19. International Journal of Environmental Research and Public Health, 17(12), 4360.

Bauman, A. E., Reis, R. S., Sallis, J. F., Wells, J. C., Loos, R. J., Martin, B. W., \& Lancet Physical Activity Series Working Group. (2012). Correlates of physical activity: why are some people physically active and others not?. The Lancet, 380(9838), 258-271.

Castañeda-Babarro, A., Arbillaga-Etxarri, A., GutiérrezSantamaría, B., \& Coca, A. (2020). Physical activity change during COVID-19 confinement. International Journal of Environmental Research and Public Health, 17(18), 6878.

Cao, X. (2020). COVID-19: immunopathology and its implications for therapy. Nature Reviews Immunology, 20(5), 269-270.

Chen, P., Mao, L., Nassis, G. P., Harmer, P., Ainsworth, B. E., \& Li, F. (2020). Coronavirus disease (COVID-19): The need to maintain regular physical activity while taking precautions. Journal of Sport and Health Science, 9(2), 103.

Craig, C. L., Marshall, A. L., Sjöström, M., Bauman, A. E., Booth, M. L., Ainsworth, B. E., ... \& Oja, P. (2003). International physical activity questionnaire: 12 -country reliability and validity. Medicine \& Science in Sports \& Exercise, 35(8), 1381-1395.

Di Renzo, L., Gualtieri, P., Pivari, F., Soldati, L., Attinà, A., Cinelli, G., ... \& De Lorenzo, A. (2020). Eating habits and lifestyle changes during COVID-19 lockdown: an Italian survey. Journal of Translational Medicine, 18, 1-15.

Engebretsen, L., Bahr, R., Cook, J. L., Derman, W., Emery, C. A., Finch, C. F., ... \& Steffen, K. (2014). The IOC Centres of Excellence bring prevention to sports medicine. British Journal of Sports Medicine, 48(17), 1270-1275.
Fat, L. N., Scholes, S., Boniface, S., Mindell, J., \& Stewart-Brown, S. (2017). Evaluating and establishing national norms for mental wellbeing using the short Warwick-Edinburgh Mental Wellbeing Scale (SWEMWBS): findings from the Health Survey for England. Quality of Life Research, 26(5), 1129-1144.

Frank, A., Fatke, B., Frank, W., Förstl, H., \& Hölzle, P. (2020). Depression, dependence and prices of the COVID-19-Crisis. Brain, behavior, and immunity, 87, 99

Gallo, L. A., Gallo, T. F., Young, S. L., Moritz, K. M., \& Akison, L. K. (2020). The impact of isolation measures due to COVID-19 on energy intake and physical activity levels in Australian university students. Nutrients, 12(6), 1865.

Hallal, P. C., Andersen, L. B., Bull, F. C., Guthold, R., Haskell, W., Ekelund, U., \& Lancet Physical Activity Series Working Group. (2012). Global physical activity levels: surveillance progress, pitfalls, and prospects. The Lancet, 380(9838), 247257.

Hoffmann, B., Kobel, S., Wartha, O., Kettner, S., Dreyhaupt, J., \& Steinacker, J. M. (2019). High sedentary time in children is not only due to screen media use: A cross-sectional study. $B M C$ Pediatrics, 19(1), 1-9.

Hossain, M. M., Tasnim, S., Sultana, A., Faizah, F., Mazumder, H., Zou, L., ... \& Ma, P. (2020). Epidemiology of mental health problems in COVID-19: a review. F1000Research, 9.

Ji, J. G., Kim, K. B., \& Kwak, Y. S. (2020). The practical impacts of exercise-intervention on COVID-19 pandemic. Exercise Science, 29(4), 339-346.

Jukic, I., Calleja-González, J., Cos, F., Cuzzolin, F., Olmo, J., Terrados, N., ... \& Alcaraz, P. E. (2020). Strategies and solutions for team sports athletes in isolation due to COVID-19. Sports, 8(4), 56.

Kim, C. (2021). Exercise Science and COVID-19. Exercise Science, $30(1), 1-2$.

Kobayashi, L. C., Steptoe, A. (2018). Social Isolation, Loneliness, and Health Behaviors at Older Ages: Longitudinal Cohort Study. Ann. Behav. Med., 52(7), 582-593.

Lu, R., Zhao, X., Li, J., Niu, P., Yang, B., Wu, H., ... \& Tan, W. (2020). Genomic characterisation and epidemiology of 2019 novel coronavirus: implications for virus origins and receptor binding. The Lancet, 395(10224), 565-574.

Mann, R. H., Clift, B. C., Boykoff, J., \& Bekker, S. (2020). Athletes as community; athletes in community: covid-19, sporting megaevents and athlete health protection. British Journal of Sports Medicine, 54(18), 1071-1072.

Mehrsafar, A. H., Gazerani, P., Zadeh, A. M., \& Sánchez, J. C. J. (2020). Addressing potential impact of COVID-19 pandemic on physical and mental health of elite athletes. Brain, Behavior, and Immunity, 87, 147-148

Mujika, I., \& Padilla, S. (2000). Detraining: loss of training-induced physiological and performance adaptations. Part I. Sports Medicine, 30(2), 79-87. 
De Oliveira Neto, L., Elsangedy, H. M., de Oliveira Tavares, V. D., Teixeira, C. V. L. S., Behm, D. G., \& Da Silva-Grigoletto, M. E. (2020). \# TrainingInHome-Home-based training during COVID-19 (SARS-COV2) pandemic: physical exercise and behavior-based approach. Revista Brasileira de Fisiologia do Exercí cio, 19(2), 9-19.

Reardon, C. L., Hainline, B., Aron, C. M., Baron, D., Baum, A. L., Bindra, A., ... \& Engebretsen, L. (2019). Mental health in elite athletes: International Olympic Committee consensus statement (2019). British journal of sports medicine, 53(11), 667-699.

Sarto, F., Impellizzeri, F. M., Spörri, J., Porcelli, S., Olmo, J., Requena, B., ... \& Franchi, M. V. (2020). Impact of potential physiological changes due to COVID-19 home confinement on athlete health protection in elite sports: a call for awareness in sports programming. Sports Medicine, 50, 1417-1419.

Silva, J. R., Brito, J., Akenhead, R., \& Nassis, G. P. (2016). The transition period in soccer: a window of opportunity. Sports Medicine, 46(3), 305-313.

Schrempft, S., Jackowska, M., Hamer, M., \& Steptoe, A. (2019). Associations between social isolation, loneliness, and objective physical activity in older men and women. BMC Public Health, 19(1), 1-10.

Thabrew, H., Stasiak, K., Bavin, L. M., Frampton, C., \& Merry, S. (2018). Validation of the mood and feelings questionnaire (mfq) and short mood and feelings questionnaire (smfq) in new zealand help-seeking adolescents. International Journal of Methods in Psychiatric Research, 27(3), e1610.

Toresdahl, B. G., \& Asif, I. M. (2020). Coronavirus disease 2019 (COVID-19): considerations for the competitive athlete. Sports Health, 12(3), 221-224.

WHO Director Media Briefing on Covid-19. (2020). Available online: https://www.who.int/director-general/speeches/detail/ who-director-general-s-opening-remarks-at-the-media-briefingon-covid-19 (accessed on 11 March 2020).

World Health Organization. (2020). Report of the WHO-China joint mission on coronavirus disease 2019 (COVID-19). https:// www.who.int/publications/i/item/report-of-the-who-china-jointmission-on-coronavirus-disease-2019-(covid-19). Accessed March 23, 2020.

Wu, Z., \& McGoogan, J. M. (2020). Characteristics of and important lessons from the coronavirus disease 2019 (COVID-19) outbreak in China: summary of a report of 72314 cases from the Chinese Center for Disease Control and Prevention. Jama, 323(13), 12391242.

Yousfi, N., Bragazzi, N. L., Briki, W., Zmijewski, P., \& Chamari, K. (2020). The COVID-19 pandemic: how to maintain a healthy immune system during the lockdown-a multidisciplinary approach with special focus on athletes. Biology of sport, 37(3), 211. 


\section{Coronavirus Pandemic 이후 신체활동 및 식습관 변화 : 국내 엘리트 청소년선수 대상 온라인 조사}

성준영1, 박상섭1, 오태웅 2

1 공군사관학교 조교수

2 용인대학교 부교수

[목적] 이 연구의 목적은 COVID-19 대유행 전후의 엘리트 성인 선수들의 활동과 식습관을 조사하여 엘리트 청소년 선수들 에게 COVID-19가 미치는 영향을 파악하는 것이었다.

[방법] 총 917명의 엘리트 청소년 선수들을 대상으로 실시되었으며, 19 개의 스포츠와 6 개의 그룹으로 분류하였다. 설문 지는 COVID-19 이전과 이후의 신체 활동, 수면 및 식습관에 대한 인구통계학적 요인 및 신체활동, 식습관에 관한 문항 이 포함되어 총 44 개 설문문항으로 구성되었다. 모든 자료의 통계적 유의수준 $p<0.05$ 로 설정하였다.

[결과] COVID-19 이후 모든 종목에서 고강도 및 중간 강도의 활동이 감소했다. 그러나 저강도 활동은 거의 모든 종목에 서 증가했다. 또한 모든 종목에서 앉아 있는 시간이 증가했으며, 식사 횟수는 종목마다 차이를 보였고, 모든 종목에서 경 기 횟수는 감소한 것을 확인하였다.

[결론] COVID-19는 끝난 듯 보이지만 아직 끝나지 않았다. 선수들은 원래 능력에 근접한 후 신체적, 생리학적 및 심리적 상태를 유지하는 최선의 방법을 찾는 것이 매우 중요하며. 이점은 COVID-19 이후 선수 복귀에 가장 큰 영향을 미칠 것 으로 판단된다.

주요어

COVID-19, 신체활동변화, 식습관 변화, 엘리트 청소년 선수, 설문조사 